\title{
The prevalence and factors associated with malnutrition among infants with cleft palate and/or lip at a hospital in Uganda: a cross-sectional study
}

\author{
Martin Tungotyo ${ }^{1 *}$, Daniel Atwine ${ }^{1}$, Deborah Nanjebe ${ }^{1}$, Andrew Hodges ${ }^{2}$ and Martin Situma ${ }^{1}$
}

\begin{abstract}
Background: To determine the prevalence and factors associated with malnutrition among infants with Cleft palate and/or cleft lip (CP+/-L) at Comprehensive Rehabilitation for Uganda Hospital (CoRSU) in Uganda.

Methods: This was a cross-sectional study done on infants with $\mathrm{CP}+/-\mathrm{L}$ and their caretakers admitted between November 2013 and October 2014 at CoRSU hospital which was the study setting. A questionnaire was answered by the infants' caretakers. The main outcome measure, malnutrition was defined and classified based on Z-scores obtained using the W.H.O Z-calculator in which weights of the infants in kilograms and lengths in centimeters respectively were placed. The values obtained were expressed as a proportion using all enrolled infants with $\mathrm{CP}+/ \mathrm{L}$ as denominator. Multivariable analysis was used to determine the risk factors.

Results: A total of 44 infants with CP+/-L were enrolled. Of these, $77 \%$ were below 4 months of age and $97.7 \%$ were immunized. The male-to-female ratio was 1.06:1. About $59 \%$ had unilateral CP+/-L. A total of $93.2 \%$ were delivered at term with $69.4 \%$ having a birth weight greater than $3 \mathrm{~kg}$. Generally, $68 \%$ were malnourished, with the highest burden among females (71.4\%), infants below 4 months (73.5\%) and those with unilateral CP+/-L (77\%). About $57 \%$ had moderate-to-severe malnutrition. There was delayed supplementation to breast milk, with cow-milk as the main supplemental feed for all the infants. In the multivariable analysis, factors associated with malnutrition included, having caretakers lacking nutritional information post-delivery $(O R=3.8, p=0.17)$, low birth weight $(O R=3.4, p=0.20)$, and having less than 10 feeds/day $(O R=4.9, p=0.09)$.

Conclusion: $\mathrm{CP}+/$-L infants born in Uganda suffer a high-burden of malnutrition. Preventional strategies are needed with focus on proper feeding information. Research on cost-effective feeds, feeding methods and reasons behind gender disparities in these infants is also required.
\end{abstract}

Keywords: Cleft palate, Infant, Malnutrition

\section{Background}

Cleft palate and/or cleft lip $(\mathrm{CP}+/-\mathrm{L})$ are among the most common congenital anomalies, with an incidence of $1 / 1000$ live births globally [1] and 0.73/1000 live births in Uganda [2]. Children with $\mathrm{CP}+/-\mathrm{L}$ are more prone to malnutrition compared to those with only Cleft Lip (CL) [3]. The prevalence of malnutrition among infants with $\mathrm{CP}+/ \mathrm{L}$ in the literature varies between 30

\footnotetext{
* Correspondence: mtungotyo@yahoo.com

${ }^{1}$ Mbarara University of Science and Technology (M.U.S.T), Mbarara, Uganda Full list of author information is available at the end of the article
}

and $50 \%[4,5]$. However, information on the prevalence of malnutrition among infants with $\mathrm{CP}+/-\mathrm{L}$ in Africa is rare.

Malnutrition in these children with $\mathrm{CP}+/-\mathrm{L}$ is majorly associated with feeding difficulties including the failure to generate sufficient suction pressure during feeding hence affecting the attachment to the breast/artificial nipple, milk extraction, bolus organization and retention of the bolus before swallow initiation [6]. Malnutrition and infection are interlinked as malnutrition is the primary cause of immunodeficiency worldwide and is 
therefore responsible for the high mortality of children less than five years old who die as a result of infectious diseases [7]. Numerous feeding interventions have been described in the literature for infants born with a cleft palate. A study done in the UK showed a reduction in failure to thrive among infants with $\mathrm{CP}+/-\mathrm{L}$ after implementation of an early feeding program that involved domiciliary visits, breast feeding support, feeding education and monitoring of growth [6].

Despite the availability of surgical corrective interventions, few $\mathrm{CP}+/-\mathrm{L}$ children are returned for their cleft palate surgical operation (usually after six months of age) in our setting a phenomenon hypothesized to be due to a likelihood of death before scheduled date of operation potentially due to consequences of malnutrition [8]. Good nutrition is also key in infants with $\mathrm{CP}+/ \mathrm{L}$ given its role in quickening wound healing post-operatively [9].

However, adequate information on the prevalence and factors associated with malnutrition in $\mathrm{CP}+/-\mathrm{L}$ infants is still lacking in our setting.

In this study we aimed at establishing the prevalence and associated factors of malnutrition among infants with $\mathrm{CP}+/-\mathrm{L}$ at CoRSU hospital.

\section{Methods}

\section{Aim}

Determine the prevalence and associated factors of malnutrition among infants with $\mathrm{CP}+/-\mathrm{L}$ at CoRSU Hospital.

\section{Study design and setting}

Across sectional study was carried out at Comprehensive Rehabilitation Services of Uganda (CoRSU) Hospital, a specialized plastic and reconstructive, as well as orthopedic surgery private facility. It is located along Entebbe road. They offer free cleft surgery and receive patients not only from Uganda but from other countries including South Sudan.

\section{Study population}

A total of 44 admitted infants with $\mathrm{CP}+/-\mathrm{L}$ between November 2013 and October 2014were consecutively enrolled in the study after obtaining consent from the primary caretakers. There were no primary caretakers that declined to participate or withdraw from the study during the study period.

\section{Data collection and management}

A pre-tested semi-structured questionnaire was developed and administered by trained research nurses to all caretakers of infants with $\mathrm{CP}+/-\mathrm{L}$. The questionnaire included caretaker and infant's baseline characteristics, and infant's nutritional characteristics. The post delivery nutritional information sought from the caregiver included, whether the caregiver had been advised on any techniques, positions and options available for feeding their infant. Information that was also sought regarding the feeding of the infants included the type of feed and how often it was given. Infant's clinical examination including type of cleft palate and anthropometry measurements was done by an experienced doctor. Anthropometry included weights and lengths done to the nearest $0.01 \mathrm{~kg}$ and $0.1 \mathrm{~cm}$ respectively using a digital weighing scale and a length board. Infants who were found to have low weights for length after comparing with the N.C.H.S reference values as required by W.H.O were then sent to the nutrition unit at the hospital as per the protocol. Double-data entry and validation were done using EpiData software (version 3.1, EpiData Association, Odense, Denmark).

\section{Data analysis}

Means and proportions were used to describe the sociodemographic characteristics of the infants with $\mathrm{CP}+/-\mathrm{L}$ and their caregiver. Nutritional characteristics were stratified using a cut off of four months which was chosen arbitrarily. Weight-for-length Z-scores were calculated using a W.H.O Z-calculator. The prevalence and severity of malnutrition was expressed as percentages with corresponding 95\% Confidence Intervals. Classification of malnutrition based on severity followed the standard as recommended by WHO.

Chi-square and logistic regression was carried out for analysis of associations. All variables with $\mathrm{p}$-value $\leq 0.2$ were included in multivariable analysis. A significance level of $5 \%$ was considered. Unadjusted and adjusted Odds ratios with corresponding 95\% CI were reported.

\section{Results}

\section{Caretaker and infant characteristics}

The caretakers were predominantly mothers $(98 \%)$, aged less than 30 years (66\%), HIV negative (79.6\%), and had delivered from a Health facility (68.2\%). Majority had acquired some post-delivery nutritional information from a health facility (81.5\%). About half had a primary level of education (54.6\%). The infants were predominantly below 4 months of age $(\sim 77 \%)$ and immunized (97.7\%). The infants' male-to-female ratio was 1.06:1. Most infants had unilateral CP+/-L (59.1\%), were delivered at term (93.2\%) and had a birth weight of more than $3 \mathrm{~kg}$ (69.4\%). See Table 1.

\section{Nutritional characteristics of the infants}

A total of $17(50 \%)$ versus $4(40 \%)$ infants below and above 4 months respectively were solely breastfeeding. Complementary feeding was reported in 17 versus 4 infants below and above 4 months respectively. Cow's milk was the most commonly used complementary feed. About half of the mothers reported inability of the baby to suckle as the main reason for not breast feeding. See Table 2. 
Table 1 Caretaker and Infant baseline characteristics

\begin{tabular}{|c|c|}
\hline Variable & $\begin{array}{l}\mathrm{n}(\%) \\
\mathrm{N}=44\end{array}$ \\
\hline \multicolumn{2}{|l|}{ Caretaker Characteristics } \\
\hline Median age in years [IQR] & $25.5[21.5-32.0]$ \\
\hline \multicolumn{2}{|l|}{ Age categories of caregiver in years } \\
\hline$<25$ & $18(40.9)$ \\
\hline $25-29$ & $11(25.0)$ \\
\hline 30 or + & $15(34.1)$ \\
\hline Gender, Female & $43(97.7)$ \\
\hline \multicolumn{2}{|l|}{ Level of education } \\
\hline Tertiary & $3(6.8)$ \\
\hline Secondary & $15(34.1)$ \\
\hline Primary & $24(54.6)$ \\
\hline Uneducated & $2(4.6)$ \\
\hline \multicolumn{2}{|l|}{ HIV status } \\
\hline Positive & $3(6.8)$ \\
\hline Negative & $35(79.6)$ \\
\hline Unknown & $6(13.6)$ \\
\hline Acquired nutrition information post-delivery & $27(61.4)$ \\
\hline \multicolumn{2}{|l|}{ Infant characteristics } \\
\hline Median age in months (IQR) & $1[1.0-3.0]$ \\
\hline \multicolumn{2}{|l|}{ Age categories in months } \\
\hline$<4$ & $34(77.3)$ \\
\hline $4-10$ & $10(22.7)$ \\
\hline Gender, Male & $23(52.3)$ \\
\hline Mean birth weight in Kg (SD) & $3.2(0.8)$ \\
\hline \multicolumn{2}{|l|}{ Birth weight category in $\mathrm{Kg}$} \\
\hline$<3$ & $11(30.6)$ \\
\hline 3 or + & $25(69.4)$ \\
\hline Presence of other congenital anomalies & $10(22.7)$ \\
\hline Immunized & $42(97.7)$ \\
\hline \multicolumn{2}{|l|}{ Category of cleft } \\
\hline Unilateral cleft palate and/or lip & $26(59.1)$ \\
\hline Bilateral cleft lip and palate & $18(40.9)$ \\
\hline
\end{tabular}

\section{Magnitude of malnutrition}

About 30 infants (68.2\%; 95\%CI: 53.9-82.5) were malnourished, with the highest burden among females (71.4\%), infants below 4 months $(73.5 \%)$ and infants with unilateral CP+/-L (77\%). Generally, 57\% had moderate-to-severe malnutrition (See Table 3).

\section{Associations of malnutrition}

Infants whose caretakers never obtained any nutritional information post-delivery had 3.8 times higher odds of having malnutrition $(\mathrm{OR}=3.8$; [95\% CI: 0.57-25.28], $\mathrm{p}=$ 0.17 ) as compared to their counterparts. Also, infants
Table 2 The nutritional history of infants with cleft palate stratified by age

\begin{tabular}{|c|c|c|}
\hline \multirow[t]{3}{*}{ Variable } & \multicolumn{2}{|c|}{ Age Category in Months } \\
\hline & $<4$ & $4-10$ \\
\hline & n (\%) & n (\%) \\
\hline \multicolumn{3}{|l|}{ Most common feeding pattern } \\
\hline Breast feeding & $17(50.0)$ & $4(40.0)$ \\
\hline Complimentary milk & $17(50.0)$ & $6(60.0)$ \\
\hline \multicolumn{3}{|l|}{ Type of complimentary milk } \\
\hline Cow & $13(76.5)$ & $6(100.0)$ \\
\hline Formula & $4(23.5)$ & $0(0.0)$ \\
\hline \multicolumn{3}{|l|}{ Reasons for not breastfeeding } \\
\hline Mother has no milk & $6(17.7)$ & $1(10.0)$ \\
\hline Baby unable to suckle & $19(55.9)$ & $5(50.0)$ \\
\hline Baby doesn't take enough & $2(5.9)$ & $1(10.0)$ \\
\hline No response & $7(20.6)$ & $3(30.0)$ \\
\hline Mean feeds per day (SD) & $10(1.5)$ & $9.2(1.6)$ \\
\hline \multicolumn{3}{|l|}{ Category of feeds per day } \\
\hline$<10$ & $8(23.5)$ & $5(50.0)$ \\
\hline 10 or + & $26(76.5)$ & $5(50.0)$ \\
\hline
\end{tabular}

who had less than 10 feeds per day had 4.9 times higher odds of having malnutrition $(\mathrm{OR}=4.9$; [95\% CI: $0.78-$ 31.13], $\mathrm{p}=0.09$ ) as compared to those with above 10 feeds/day. Infants born with a low birth weight had 3.4 times higher odds of having malnutrition $(\mathrm{p}=0.2$, OR3.4 [95\% CI: 0.52-21.71]. see Table 4.

\section{Discussion}

The prevalence of malnutrition among infants with CP $+/-\mathrm{L}$ in this study was found to be $68 \%$. Female infants

Table 3 The Prevalence of Malnutrition

\begin{tabular}{lll}
\hline Type of Prevalence & Number & $\%[95 \% \mathrm{Cl}]$ \\
\hline $\begin{array}{l}\text { Overall Prevalence } \\
\text { Prevalence by severity }\end{array}$ & 30 & $68.2[53.9-82.5]$ \\
$\quad$ Mild & 5 & $11.4[1.6-21.1]$ \\
$\quad$ Moderate & 8 & $18.2[6.3-30.0]$ \\
$\quad$ Severe & 17 & $38.6[23.7-53.6]$ \\
Prevalence by age (months) & & \\
$\quad<4$ & 25 & $73.5[57.9-89.2]$ \\
$\quad 4-10$ & 5 & $50.0[12.3-87.7]$ \\
Prevalence by infants gender & & \\
$\quad \begin{array}{l}\text { Male } \\
\text { Female }\end{array}$ & 15 & $65.2[44.2-86.3]$ \\
Prevalence by type of cleft palate & 15 & $71.4[50.4-92.3]$ \\
$\quad \begin{array}{l}\text { Unilateral } \\
\text { Bilateral }\end{array}$ & 20 & $76.9[59.6-94.3]$ \\
\hline
\end{tabular}


less than four months were the most affected. $50 \%$ of the infants were solely breast-fed despite having a $\mathrm{CP}$ $+/$ - L, and those that were on complementary feeding were majorly on a cows' milk diet.

The prevalence recorded in the study was higher than other studies done in other settings. The discrepancies could have been due to the differences in geographical location, methodology of assessing malnutrition and study tools.

Previous studies that documented lower prevalences were done in other geographical regions like the UK [5], Brazil [4] and India [10] which are generally at a better socioeconomic status.

In some studies, the standard deviation ( $\mathrm{Z}$ score) method proposed by the W.H.O. was not used to define malnutrition. In the study done in Brazil [4] the preferred method of assessment was the $10^{\text {th }}$ percentile cut offs for documenting malnutrition whereas our study, like the study by Pandya et al used standard deviations to assess malnutrition. These differences in the methods of assessment could have led to the differences in the statistics.

Some of the studies such as the one conducted by Mehkarkar and Chaudhari [10] defined their study population differently. They excluded infants with other congenital deformities whereas we defined a participant as any infant who had a $\mathrm{CP}+/ \mathrm{L}$ with or without any other congenital malformation. This could have contributed to the higher prevalence seen in our study.

The high malnutrition seen in the infants less than 4 months was probably due to the infants' inability to breastfeed adequately. This was also noted in the study done by Cubit et al [3]. Exclusive Breast feeding is recommended for all infants less than 6 months of age by W.H.O. However, the difficulties associated with breast feeding among infants with $\mathrm{CP}+/-\mathrm{L}$ are well documented [6]. Therefore, assisted feeding for infants with $\mathrm{CP}+/-\mathrm{L}$ is encouraged as it has been found to be more reliable [11]. The choices available for complementary feeding vary from cow's milk to infant formula. However, breast milk is still regarded as the milk of choice for its numerous advantages including protection against otitis media in cleft palate infants [12]. Numerous methods have been described for assisted feeding for these infants including compressible bottles, modified nipples, cups and prostheses or appliances. However, the evidence to support one particular method over the others has been found to be weak [6]. As the methods of assisted feeding were not assessed in this study, another study may therefore be required to assess the most applicable feeding method to assist infants born with $\mathrm{CP}+/-\mathrm{L}$ in our setting in order to reduce the rate of malnutrition.

The prevalence of malnutrition among females was higher than that of males and the overall prevalence. The cause of this imbalance needs further investigation as very few studies evaluating the problem have focused on gender differences. Literature from elsewhere seem to point to a gender imbalance as regards to children's nutrition and access to health care. A study done in Pakistan showed that male children were favored more in the allocation of health care compared to the females [13]. Could the same cultural anomaly have led to more access to health care for the male infant compared to the female and therefore contributed to more malnourished females? Also, most of the mothers in our study were educated up to primary school level. The fact that they did not get further education could have limited their access to better education against some of these cultural anomalies.

Malnutrition was also found to be higher among the unilateral $\mathrm{CP}+/-\mathrm{L}$ infants compared to their bilateral counterparts. Could the severe facial disfigurement and apparent difficulty in breast feeding in bilateral $\mathrm{CP}+/-\mathrm{L}$ have forced the mothers to seek medical attention earlier than their unilateral counterparts? This could have led to the differences observed.

Regarding the associated factors, the lack of provision of nutritional information was associated with malnutrition among our infants with $\mathrm{CP}+/-\mathrm{L}$. Provision of nutritional information has been shown to be associated with improved outcomes. In the study performed in the United Kingdom [5], they noted a decline in malnutrition after instituting a feeding support nurse whose role was to provide nutritional information and follow up among other feeding interventions.

Our study noted that children who had fewer than 10 feeds a day were more likely to be malnourished. This could have been due to failure of the infant to breastfeed. The most common reason for not breast feeding was failure of the infants to suckle (Table 3) which has been documented elsewhere [14] as a common reason for not breastfeeding infants with a cleft palate. Even though it was not investigated, the fear of the task of feeding their cleft palate infants has been documented as a contributor for malnutrition [6].

The Study showed that the risk of malnutrition was higher for $\mathrm{CP}+/$-L infants born with a low birth weight. This finding is similar to studies done in Oman [15] and Malawi [16]. There is need therefore for the integration of other health services to ensure mothers deliver healthy infants as maternal environmental factors such as smoking, indoor air pollution, infections such as malaria as well as underlying social factors such as poverty are important contributors to low birth weight [17].

The combination of lack of provision of nutritional information following the delivery of a $\mathrm{CP}+/ \mathrm{L}$ infant, number of feeds less than 10 received per day by the $\mathrm{CP}+/-\mathrm{L}$ infant and low birth weight was found to be 
Table 4 Factors influencing malnutrition among Infants with cleft palates

\begin{tabular}{|c|c|c|c|c|c|}
\hline Variable & Normal n(\%) & Malnourished n(\%) & Unadjusted OR [95\% Cl] & Adjusted OR [95\% Cl] & $P$ \\
\hline \multicolumn{6}{|l|}{ Age of caregiver in years } \\
\hline$<25$ & $4(22.2)$ & $14(77.8)$ & 1 & & \\
\hline $25-29$ & $4(36.4)$ & $7(63.6)$ & $0.5[0.10-2.62]$ & & \\
\hline 30 or + & $6(40.0)$ & $9(60.0)$ & $0.4[0.09-1.95]$ & & \\
\hline \multicolumn{6}{|l|}{ Level of education } \\
\hline Tertiary & $1(33.3)$ & $2(66.7)$ & 1 & & \\
\hline Secondary & $7(46.7)$ & $8(53.3)$ & $0.6[0.04-7.74]$ & & \\
\hline Primary & $6(25.0)$ & $18(75.0)$ & $1.5[0.11-19.64]$ & & \\
\hline Uneducated & $0(0.0)$ & $2(100)$ & 1 & & \\
\hline \multicolumn{6}{|l|}{ HIV status } \\
\hline Positive & $2(66.7)$ & $1(33.3)$ & 1 & & \\
\hline Negative & $10(28.6)$ & $25(71.4)$ & $5[0.41-61.52]$ & & \\
\hline Unknown & $2(33.3)$ & $4(66.7)$ & $4[0.21-75.66]$ & & \\
\hline \multicolumn{6}{|l|}{ Obtained post-delivery information } \\
\hline Yes & $11(40.7)$ & $16(59.3)$ & 1 & & \\
\hline No & $3(17.7)$ & $14(82.4)$ & $3.2[0.74-13.87]$ & $3.8[0.57-25.28]$ & 0.17 \\
\hline \multicolumn{6}{|l|}{ Most common feeding pattern } \\
\hline Breast milk-based & $5(23.8)$ & $16(76.2)$ & 1 & & \\
\hline Complimentary milk & $9(39.1)$ & $14(60.9)$ & $0.5[0.13-1.80]$ & & \\
\hline \multicolumn{6}{|l|}{ Type of complimentary milk } \\
\hline Cow & $11(35.5)$ & $20(64.5)$ & 1 & & \\
\hline Formula & $2(33.3)$ & $4(66.7)$ & $1.1[0.17-7.00]$ & & \\
\hline \multicolumn{6}{|l|}{ Reasons for not breastfeeding } \\
\hline Mother has no milk & $2(28.6)$ & $5(71.4)$ & 1 & & \\
\hline Baby unable to suckle & $7(29.2)$ & $17(70.8)$ & $1.0[0.15-6.25]$ & & \\
\hline Baby doesn't take enough & $1(33.3)$ & $2(66.7)$ & $0.8[0.04-14.64]$ & & \\
\hline \multicolumn{6}{|l|}{ Category of feeds per day } \\
\hline$<10$ & $2(15.4)$ & $11(84.6)$ & $3.5[0.65-18.47]$ & $4.9[0.78-31.13]$ & 0.09 \\
\hline 10 or + & $12(38.7)$ & $19(61.3)$ & 1 & & \\
\hline \multicolumn{6}{|l|}{ Age of baby in months } \\
\hline$<4$ & $9(26.5)$ & $25(73.5)$ & 1 & & \\
\hline $4-10$ & $5(50.0)$ & $5(50.0)$ & $0.4[0.08-1.54]$ & & \\
\hline \multicolumn{6}{|l|}{ Gender of baby } \\
\hline Male & $8(34.8)$ & $15(65.2)$ & 1 & & \\
\hline Female & $6(28.6)$ & $15(71.4)$ & $1.3[0.37-4.78]$ & & \\
\hline \multicolumn{6}{|l|}{ Birth weight category in $\mathrm{Kg}$} \\
\hline$<3$ & $2(18.2)$ & $9(81.8)$ & $3.5[0.63-19.82]$ & $3.4[0.52-21.71]$ & 0.2 \\
\hline 3 or + & $11(44.0)$ & $14(56.0)$ & 1 & & \\
\hline \multicolumn{6}{|l|}{ Other congenital anomalies } \\
\hline Yes & $2(20.0)$ & $8(80.0)$ & $2.2[0.40-11.96]$ & & \\
\hline No & $12(35.3)$ & $22(64.7)$ & 1 & & \\
\hline \multicolumn{6}{|l|}{ Category of cleft } \\
\hline Unilateral cleft palate and/or lip & $6(23.1)$ & $20(76.9)$ & 1 & & \\
\hline Bilateral cleft lip and palate & $8(44.4)$ & $10(25.6)$ & $0.4[0.10-1.38]$ & & \\
\hline
\end{tabular}


the greatest predictor of malnutrition among $\mathrm{CP}+/-\mathrm{L}$ infants.

This is the first study in our setting to explore the prevalence and severity of malnutrition with its associated factors among infants with $\mathrm{CP}+/-\mathrm{L}$.

\section{Conclusions}

This work described malnutrition among infants with $\mathrm{CP}$ +/-L at a specialized plastic surgery hospital in Uganda.

Like other studies previously reported, there was a high prevalence of malnutrition in this population. The low study participants obtained for the study was a major study limitation. However, the Low recruitment of study subjects concurred with studies done in a similar setting that showed few infants with $\mathrm{CP}+/ \mathrm{L}$ were being seen at the time of their operation probably because they were dying earlier [8]. Malnutrition was hypothesized to have contributed to their deaths. Even though the low numbers could have affected the power of the study, the high prevalence of malnutrition among $\mathrm{CP}+/-\mathrm{L}$ infants showed clinical significance.

We managed to describe the severity of malnutrition according to the WHO classification for malnutrition which no other studies had done in our setting. The fact that most children had severe malnutrition further strengthened the need for aggressive nutritional management for infants with $\mathrm{CP}+/-\mathrm{L}$ with the help of the motivated caretaker.

Many of the factors associated with $\mathrm{CP}+/-\mathrm{L}$ were directly related to the caregiver status. There is therefore need for integration of everyday healthcare practices of the caregivers into $\mathrm{CP}+/-\mathrm{L}$ surgical services to reduce the risk of malnutrition among these infants.

Finally, longitudinal and interventional studies will be needed to better determine causation in many of the factors noted and to improve outcomes so that we prevent malnutrition in infants with $\mathrm{CP}+/-\mathrm{L}$.

\section{Recommendations}

Proper Nutritional information should be readily available for all mothers who give birth to infants with $\mathrm{CP}+/-\mathrm{L}$.

The nutritional information available should include methods of assisted feeding, feeding techniques such as positioning and follow up. Further studies may be required to assess the different modalities for assisted feeding in order to come up with the most applicable method for these caretakers to adopt in our setting.

There is need to increase public awareness of the likely hood of malnutrition among infants born with a cleft palate. This would help emphasize nutrition both for the caretakers and care providers of these infants.

Further studies are required to elucidate the role of culture in access of health care as regards the gender of the infants and perceptions of the cleft conditions.
There is need to strengthen the link between general health care and maternal health care in our setting. We need to re-emphasize for example the need for proper maternal nutrition, the avoidance of smoking in pregnancy among others.

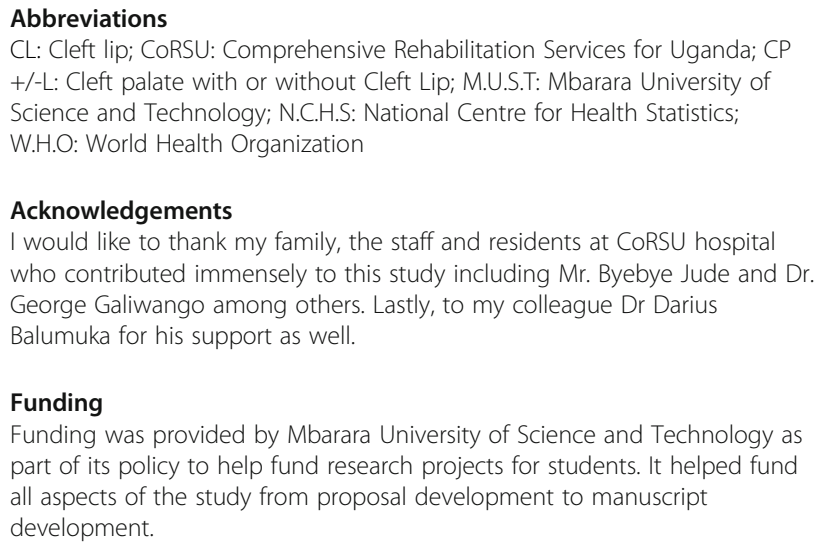

\section{Acknowledgements}

I would like to thank my family, the staff and residents at CoRSU hospital who contributed immensely to this study including Mr. Byebye Jude and Dr. George Galiwango among others. Lastly, to my colleague Dr Darius Balumuka for his support as well.

Funding

Funding was provided by Mbarara University of Science and Technology as part of its policy to help fund research projects for students. It helped fund all aspects of the study from proposal development to manuscript development.

\section{Availability of data and materials}

Data from which the conclusions within this manuscript were made will unfortunately not be made available in the public repositories and the main paper. The author is still using the data set to carry out more research.

\section{Authors' contributions}

MT was the principal investigator of the study. He came up with the concept and design of the study. MT was also responsible for training research assistants. DA was responsible for data analysis and statistical interpretation of the results. DN was responsible for manuscript development and editing once the most appropriate journal was chosen. AH was the internal supervisor of the research at CoRSU hospital. He provided overall guidance of the research. MS was the external supervisor from MUST. He provided guidance and advice as regards the research polices and guidelines from the University. All authors read and approved the final manuscript.

\section{Author information}

The author is a locally trained plastic and reconstructive surgeon currently employed by M.U.S.T as a lecturer in the department of Surgery where he has been for the last one year. This research paper was done as a requirement for the achievement of the Masters of Medicine in Plastic and Reconstructive surgery degree at the university.

Competing interests

The authors declare that they have no competing interests.

Consent for publication

All primary caretakers that consented to the study also consented to publication of the results of the study.

\section{Ethics approval and consent to participate}

Ethics approval was obtained from the Institutional Review Council (IRC) of Mbarara University of Science and Technology (Reference number - MUIRC- 1/7) and Uganda National Council of Science and Technology (UNCST). Consent to participate was sought from the primary caretakers of the infants that fit the inclusion criteria.

\section{Author details}

${ }^{1}$ Mbarara University of Science and Technology (M.U.S.T), Mbarara, Uganda. ${ }^{2}$ Comprehensive Rehabilitation Services for Uganda (CoRSU) Hospital, Kisubi, Uganda.

Received: 26 May 2016 Accepted: 30 December 2016 Published online: 13 January 2017 


\section{References}

1. Cunningham ML, Jerome JT. Linear growth characteristics of children with cleft lip and palate. J Pediatr. 1997;131(5):707-11.

2. Dreise $M$, Galiwango $G$, Hodges A. Incidence of Cleft Lip and Palate in Uganda. Cleft Palate Craniofac J. 2010;48(2):156-60.

3. Cubitt J, Hodges A, Galiwango G, Lierde K. Malnutrition in cleft lip and palate children in Uganda. Eur J Plast Surg. 2011;35(4):273-6.

4. Montagnoli LC, de Souza L. Growth impairment of children with different types of lip and palate clefts in the first 2 years of life: a cross-sectional study. J Pediatr (Rio J). 2005;81(6):461-5.

5. Pandya AN, Boorman JG. Failure to thrive in babies with cleft lip and palate. Br J Plast Surg. 2001;54(6):471-5.

6. Reid J. A Review of Feeding Interventions for Infants With Cleft Palate. Cleft Palate Craniofac J. 2004;41(3):268-78.

7. Katona P, Katona-Apte J. The Interaction between Nutrition and Infection. Clin Infect Dis. 2008;46(10):1582-8.

8. Wilson J, Hodges A. Cleft Lip and Palate Surgery Carried Out by One Team in Uganda: Where Have All the Palates Gone? Cleft Palate Craniofac J. 2011; 49(3):299-304.

9. Pham NV, Cox-Reijven PLM, Greve JW, Soeters PB. Application of subjective global assessment as a screening tool for malnutrition in surgical patients in Vietnam. Clin Nutr. 2006;25(1):102-8.

10. Chaudhari CG, M NS. Growth and Development of Cleft Lip and Cleft Palate Children Before and After Reconstruction Surgery. Int J Recent Trends Sci Technol. 2012;4(2):94-7.

11. Shaw WC, Bannister RP, Roberts CT. Assisted Feeding is More Reliable for Infants with Clefts-A Randomized Trial. Cleft Palate Craniofac J. 1999;36(3):262-8.

12. Paradise JL, Elster BA, Tan L. Evidence in Infants With Cleft Palate That Breast Milk Protects Against Otitis Media. Pediatrics. 1994;94(6):853.

13. Hazarika G. Gender Differences in Children's Nutrition and Access to Health Care in Pakistan. J Dev Stud. 2000;37(1):73-92.

14. Dalben GS, Costa B, Gomide MR, das Neves LT. Breast-Feeding and Sugar Intake in Babies With Cleft Lip and Palate. Cleft Palate Craniofac J. 2003; 40(1):84-7.

15. Kurup PJ, Khandekar R. Low birth weight as a determinant of protein energy malnutrition in"0-5 years" Omani children of South Batinah region, Oman. Saudi Med J. 2004;25(8):1091-6.

16. Espo M, Kulmala T, Maleta K, Cullinan T, Salin M-L, Ashorn P. Determinants of linear growth and predictors of severe stunting during infancy in rural Malawi. Acta Paediatr. 2002;91(12):1364-70.

17. Ramakrishnan U. Nutrition and low birth weight: from research to practice. Am J Clin Nutr. 2004;79(1):17-21.

\section{Submit your next manuscript to BioMed Central and we will help you at every step:}

- We accept pre-submission inquiries

- Our selector tool helps you to find the most relevant journal

- We provide round the clock customer support

- Convenient online submission

- Thorough peer review

- Inclusion in PubMed and all major indexing services

- Maximum visibility for your research

Submit your manuscript at www.biomedcentral.com/submit 